\title{
PENERAPAN MEDIA E-BOOK BEREKSTENSI EPUB UNTUK MENINGKATKAN MINAT DAN HASIL BELAJAR SISWA SMP PADA MATA PELAJARAN IPA
}

\author{
Haning Hasbiyati ${ }^{1}$ \\ ${ }^{1}$ Pendidikan Biologi, Fakultas Keguruan dan Ilmu Pendidikan, Universitas Islam Jember \\ haninghasbivati@gmail.com \\ Laila Khusnah ${ }^{2}$ \\ ${ }^{2}$ Pendidikan Biologi, Fakultas Keguruan dan Ilmu Pendidikan, Universitas Islam Jember \\ lailakhusnah@ymail.com
}

\begin{abstract}
Abstrak
Tujuan dari penelitian ini adalah untuk meningkatkan minat dan hasil belajar siswa yaitu dengan menerapkan media E-book berekstensi epub didalam smartphone sebagai media belajar yang bersifat inovatif sebagai upaya memanfaatkan kegemaran siswa menggunakan smartphone agar tetap belajar. Tujuan penelitian jangka panjang diharapkan dapat mengurangi beban pendidik dalam menyajikan informasi dalam pembelajaran karena diwakili dengan adanya $e$-book, dapat mengefektifkan dan mengefisienkan waktu pembelajaran karena tidak harus membawa banyak buku bacaan dalam bentuk fisiknya yang berat, dan dapat membantu memudahkan siswa belajar karena fitur multimedia dapat menjadi tutor. Penelitian penerapan media e-book berekstensi epub untuk meningkatkan minat dan hasil belajar siswa smp pada mata pelajaran ipa termasuk kedalam jenis penelitian kuantitatif. Analisa data dalam penelitian ini adalah analisa data kuantitatif. Data kuantitatif diperoleh dari hasil angket respon siswa dan tes kognitif siswa. Berdasarkan hasil penelitian diperoleh bahwa implementasi E-book berekstensi.epub dapat meningkatkan minat belajar sangat baik sebesar $88,61 \%$ dan dapat meningkatkan hasil belajar siswa dengan kriteria tinggi berupa gain score sebesar 0,703 pada pembelajaran IPA SMP.
\end{abstract}

Kata Kunci: E-Book, Minat, Hasil Belajar.

\begin{abstract}
The purpose of this study is to encourage and increase student learning outcomes by implementing media extension Epub eBook inside the smartphone as a medium of learning that is innovative as an effort to utilize the smartphone craze students use to keep learning. The purpose longterm research is expected to reduce the burden of teachers in presenting the information in the study because it is represented by the e-book, can streamline and minimize the learning time because they do not have to carry a lot of books in the physical form of severe, and can help facilitate student learning for multimedia features can become a tutor. Research media e-book application with extension epub to encourage and increase junior high school student learning outcomes science nature on the subjects included in quantitative research. Analysis of the data in this research is the analysis of quantitative data. Quantitative data obtained from the student questionnaire responses and cognitive tests students. The result showed that the implementation of the E-book. Epub can improve the learning interest of $88.61 \%$ is very good and can improve student learning outcomes with high criteria such as gain score of 0,703 on science teaching junior high.
\end{abstract}

Keywords: E-Book, Interest, Learning Outcomes. 


\section{Pendahuluan}

$\begin{array}{ccr}\text { Kebanyakan } & \text { siswa } & \text { masih } \\ \text { menganggap IPA } & \text { merupakan } & \text { mata }\end{array}$ pelajaran yang sulit. Beberapa guru sering memberikan inovasi dengan melakukan pembelajaran dengan berbagai model pembelajaran agar siswa tertarik dan lebih mudah memahami materi IPA. Tetapi dengan berkembangnya smartphone, beberapa siswa lebih memilih memainkan alat komunikasi smartphone di bandingkan dengan belajar dan terkadang siswa memainkan smartphone ketika guru sedang menjelaskan pelajaran. Maka kebanyakan sekolah tidak memperbolehkan siswanya membawa smartphone agar siswa dapat konsentrasi belajar di sekolah. Tetapi kegemaran siswa memainkan smartphone masih menyita waktu mereka belajar dan mengerjakan tugas rumah. Apalagi siswa SMP dalam tahap perkembanganya berada pada tahap perkembangan yang pesat dari berbagai aspek. Berdasarkan aspek kognitifnya seharusnya anak usia SMP justru mampu mengoptimalkan kemampuan intelektualnya dengan mengmbangkan proses belajar bukan malah mengganggu proses belajar. Agar pemanfaatan smartphone mampu mengakomodasi minat untuk belajar maka alternatif yang sangat mungkin dilakukan yaitu dengan memanfaatkan kecanggihan smartphone di dalam pembelajaran,karena belajar tidak hanya melalui buku terutama pembelajaran pada mata pelajaran IPA. Pembelajaran IPA menekankan pada pemberian pengalaman secara langsung. Oleh karena itu, siswa perlu dibantu untuk mengembangkan keterampilan proses.

Berdasarkan penelitian peneliti dalam melakukan pengembangan media EBook pada smartphone sebagai alternatif media pembelajaran IPA. Para guru dapat membuat sebuah buku yang bisa masuk didalam smartphone yang sering disebut dengan E-book. Beberapa keunggulan $E$ - book yaitu lebih mudah untuk dibawa dalam banyak file, guru tidak kehabisan bahan belajar untuk siswa, dapat mengurangi beban guru dalam menyajikan informasi, informasi yang diberikan melalui E-book lebih konkret dan memungkinkan pembelajaran bersifat individual pada siswa sebab tidak tergantung pada informasi yang diberikan guru. Salah satu format E-Book yang dapat digunakan pada smartphone adalah Epub (electronic publication) yang merupakan salah satu format digital book yaitu format standardisasi bentuk. Epub menggantikan peran Open eBook sebagai format buku terbuka. Epub terdiri atas file multimedia, html5, css, xhtml, xml yang dijadikan satu file dengan ekstensi epub. Format ini memiliki kelebihan didukung format audio dan video, konten interaktif, format tata letak web dinamis, pengamanan hak cipta, dan pengaturan ukuran text. Dengan harapan siswa memiliki minat belajar IPA dengan memanfaatkan kegemaran siswa dalam menggunakan smartphone agar siswa dapat meningkat hasil belajar mereka. Maka dilakukan penerapan media E-book berekstensi epub untuk meningkatkan minat dan hasil belajar siswa SMP pada mata pelajaran IPA.

\section{Metode Penelitian}

Jenis penelitian ini merupakan penelitian kuantitatif. Penerapan media EBook berekstensi epub ini hanya pada materi pertumbuhan dan perkembangan. Subyek penelitian ini adalah siswa SMP kelas VIII di SMPN 2 Yosowilangun Lumajang. Untuk memperoleh data minat dan hasil belajar siswa dalam penelitian ini, maka instrumen yang digunakan sebagai berikut.

Pertama, intrumen Angket Siswa, Angket digunakan untuk mengukur minat siswa terhadap proses pembelajaran IPA menggunakan media E-book berektensi epub. 
Kedua adalah Tes kognitif, Tes kognitif digunakan untuk mengetahui hasil belajar siswa selama proses pembelajaran IPA menggunakan media E-book berektensi.epub.

Sedangkan analisa data dalam penelitian ini adalah analisa data kuantitatif. Data kuantitatif diperoleh dari lembar angket respon/sikap siswa dan tes kognitif. Analisis data angket respon/sikap siswa. Analisa awal dihitung jumlah skor total. Setelah diketahui skor total yang diperoleh, maka dikonversi dalam prosentase.

$$
\begin{aligned}
& x_{\text {total }}=\sum x_{i} \\
& \text { Prosentase }=\frac{x_{\text {total }}}{x_{\max }} \times 100 \%
\end{aligned}
$$

Setelah dilakukan analisis awal dan konversi, selanjutnya dilakukan interpretasi data dengan menggunakan kriteria penilaian menurut Arikunto (2010), yaitu:

$$
\begin{array}{ll}
76 \%-100 \% & =\text { Sangat Baik } \\
56 \%-75 \% & =\text { Baik } \\
40 \%-55 \% & =\text { Kurang Baik } \\
0 \%-40 \% & =\text { Tidak Baik }
\end{array}
$$

Keberhasilan pengembangan e-book berekstensi .epub didukung pula oleh hasil tes kognitif yang diberikan kepada siswa, dalam hal ini dianalisis dengan menggunakan gain score ternormalisasi rata-rata, yaitu gain score rata-rata aktual dibagi dengan gain rata-rata aktual maksimum menurut Hake (2008) dalam Parno (2010) sebagai berikut.

$$
\begin{aligned}
\langle g\rangle \quad & =\frac{\%\langle\text { gain }\rangle}{\%\langle\text { gain }\rangle_{\max }} \\
& =\frac{\%\langle\text { post tes }\rangle-\%\langle\text { pretes }\rangle}{100-\%\langle\text { pretes }\rangle}
\end{aligned}
$$

Keterangan:

$$
\begin{array}{ll}
>0,7 & : \text { tinggi } \\
0,3-0,7 & : \text { medium } \\
<0,3 & : \text { rendah }
\end{array}
$$

\section{Hasil Penelitian dan Pembahasan}

Angket digunakan untuk mengukur pendapat siswa terhadap ketertarikan pada tampilan, kemudahan memahami kebahasaa dan manfaat media E-Book berekstensi epub. Pemilihan ebook dalam smartphone ini, menurut Ragawanto (2013), merupakan salah satu alternatif pemecahan permasalahan pendidikan melalui aspek penerapan Teknologi Pendidikan, yaitu dengan mendayagunakan sumber-sumber belajar yang dirancang, dikembangkan, dan dimanfaatkan dalam pembelajaran yaitu media pembelajaran yang dapat merangsang terjadinya proses pembelajaran dalam diri siswa. Hal ini sesuai dengan data angket respon siswa terhadap media E-Book berekstensi epub diperoleh kriteria sangat baik sebesar $88,61 \%$. Hasil data angket respon siswa disajikan pada Tabel 1 .

$\begin{array}{ccr}\text { Hasil belajar } & \text { merupakan } \\ \text { kemampuan } & \text { belajarnya } & \text { setelah }\end{array}$ mendapatkan pengalaman belajarnya. Untuk mendapatkan hasil belajar siswa dengan menerapkan media E-Book berekstensi epub maka desain penelitian ini mengadopsi desain 'One Group PretestPost-test Design". Subyek penelitian diberi perlakuan yang sebelumnya diberi pengukuran awal berupa tes awal (pretest), kemudian diakhir perlakuan akan diukur berupa tes akhir (post-test). Pengaruh penggunaan media E-Book berekstensi epub terhadap hasil belajar diperoleh dengan mengukur perbedaan pretest dan post-test. Hasil belajar pretest dan post-test siswa SMP pada mata pelajaran IPA dengan materi pertumbuhan dan perkembangan diperoleh disajikan pada Tabel 2. 


\section{Tabel 1. Data Hasil Angket Respon Siswa}

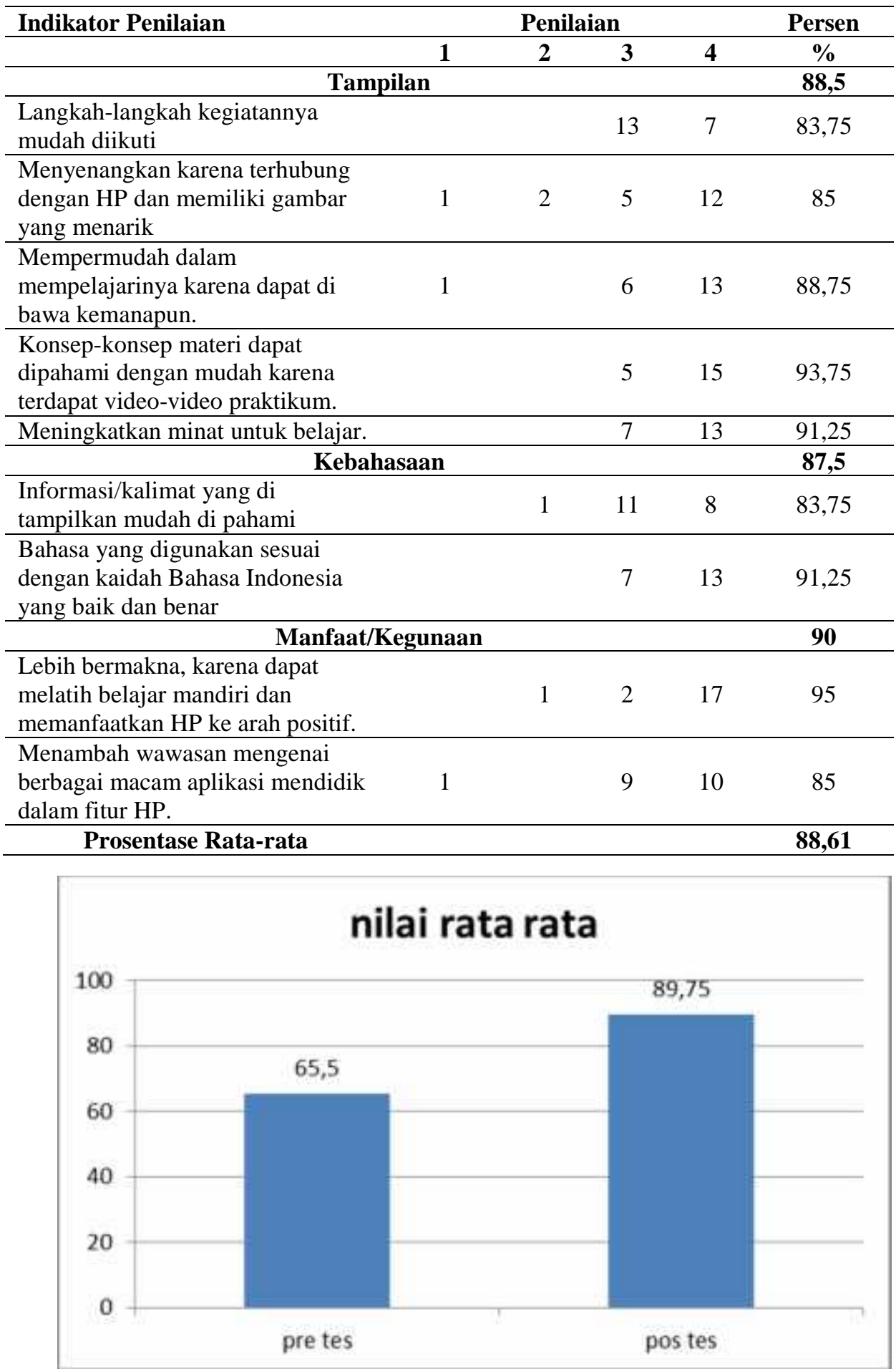

Gambar 1. Grafik Hasil Tes Kognitif Siswa 
Tabel 2. Hasil Pretest dan Post-test

\begin{tabular}{ccc}
\hline SISWA & Pre Test & Post Test \\
\hline A & 65 & 90 \\
\hline B & 65 & 90 \\
\hline C & 70 & 90 \\
\hline D & 65 & 90 \\
\hline E & 75 & 100 \\
\hline F & 70 & 95 \\
\hline G & 65 & 90 \\
\hline H & 60 & 80 \\
\hline I & 65 & 90 \\
\hline J & 70 & 90 \\
\hline K & 65 & 90 \\
\hline L & 65 & 90 \\
\hline M & 65 & 90 \\
\hline N & 70 & 90 \\
\hline O & 70 & 95 \\
\hline P & 60 & 80 \\
\hline Q & 60 & 95 \\
\hline R & 60 & 90 \\
\hline S & 65 & 90 \\
\hline T & 60 & 80 \\
\hline \% rata- rata pre test & $\mathbf{6 5 , 5}$ \\
\hline \% rata-rata post test & $\mathbf{8 9 , 7 5}$ \\
\hline & & \\
\hline
\end{tabular}

Salah satu alternatif pembelajaran yang diajukan Kurniawati (2013) adalah dengan mengembangkan bahan ajar yang bisa meningkatkan kualitas belajar siswa dalam menguasai materi pelajaran, yaitu modul. Dengan sentuhan teknologi pendidikan, modul dalam pembelajaran berkembang menjadi e-book. Perpaduan buku (modul) digital serta tuntutan adanya multimedia maka e-book berekstesi .epub sangat tepat untuk membantu keberhasilan proses pembelajaran. Hal ini sesuai dengan hasil tes kognitif yang diperoleh berupa gain score dengan kriteria keberhasilan tinggi sebesar 0,703 .
Berdasarkan grafik diatas terlihat terjadi peningkatan hasil belajar sebelum dan sesudah perlakuan penerapan media ebook berekstensi epub pada siswa SMP dalam mata pelajaran IPA. Sehingga penerapan media E-Book berekstensi epub ini diharapkan dapat memberi kontribusi mengurangi dampak negative dari kegemaran siswa menggunakan smartphone dan menjadi alternative perkembangan IPTEK utamanya pada para guru sebagai media pembelajaran IPA SMP yang menarik minat siswa.

\section{Kesimpulan dan Saran}

Berdasarkan dari hasil penelitian ini, dapat diambil kesimpulan bahwa Implementasi E-Book berekstensi epub dapat meningkatkan minat belajar sangat baik sebesar $88,61 \%$ dan dapat meningkatkan hasil belajar siswa dengan kriteria tinggi berupa gain score sebesar 0,703 pada pembelajaran IPA SMP. Penelitian ini hanya pada materi pertumbuhan dan perkembangan, untuk kedepanya penelitian dapat dilakukan pada materi-materi lain.

\section{Daftar Pustaka}

Arikunto, S. 2010. Prosedur Penelitian Suatu Penelitian Praktek. Jakarta: Rineka Cipta.

Ashyar, R. 2011. Kreatif mengembangakan Media

Pembelajaran. Jakarta: Gaung Persada Press.

Budianto, A. W. 2013. Pengembangan Media Komputer Pembelajaran Materi Tentang Ekosistem Pada Mata Pelajaran Biologi Untuk Siswa Kelas VII Di SMP Negeri 8 Kota Mojokerto. Universitas Negeri Surabaya. Jurnal Mahasiswa Teknologi Pendidikan VOL 1 NO 3. 
Kurniawati, A. 2013. Pengembangan

Modul Untuk Mata Pelajaran

Produktif Kelas X Kompetensi Keahlian Multimedia Semester 2

SMK Negeri 1 Magetan. Jurnal Mahasiswa Teknologi Pendidikan $\begin{array}{llll}\text { Vol } 1 & \text { No } & 3 & \text { (2013): }\end{array}$ http://jurnalmahasiswa.unesa.ac.id.

Ragawanto, S. T. 2013. Pengembangan

Media Web Moodle Pada Mata

Pelajaran Produktif Teknik

Komputer Dan Jaringan Bab

Mendiagnosis Permasalahan

Pengoperasian PC dan Periferal untuk Siswa Kelas X TKJ di SMK

Negeri 1 Surabaya. Jurnal

Mahasiswa Teknologi Pendidikan

$\begin{array}{lllll}\text { Vol } & 1 & \text { No } & 3\end{array}$

http://jurnalmahasiswa.unesa.ac.id.

Sugiyono, 2011. Metode Penelitian

Kuantitatif Kualitas dan $R \& D$.

Bandung: Alfabeta. 